\title{
El militarismo sudamericano tras el velo del Covid-19
}

\section{South American Militarism Behind the Veil of Covid-19}

\section{Emilse Calderón}

Emilse Calderón es docente e investigadora de la Escuela de Relaciones Internacionales, Facultad de Ciencia Política y Relaciones Internacionales, Universidad Nacional de Rosario, Argentina.

E-mail: emilsecalderon@hotmail.com

\section{resumen}

El militarismo como tendencia en América del Sur, desplegada progresivamente en la posguerra fría y con más notoriedad durante el siglo XXI, se aceleró en 2019. Ante la coyuntura instaurada por el Covid-19, es necesario preguntarse por el impacto que tendrá la convocatoria realizada por los gobiernos a los militares para abordar la crisis sanitaria provocada por la pandemia. Este artículo contextualiza el militarismo como tendencia para comprender dicho impacto potencial.

\section{summary}

Militarism as a trend in South America, progressively deployed in the post-cold war and with more notoriety during the $21 \mathrm{st}$ century, accelerated in 2019. Faced with the situation set up by Covid-19, it is necessary to ask ourselves about the impact that the call made by governments to the military to address the health crisis caused by the pandemic. This article contextualizes militarism as a tendency to understand this potential impact.

\section{palabras clave}

militarismo / pandemia / América del Sur / democracia

\section{keywords}

militarism / pandemic / South America / democracy 


\section{Introducción}

En el mundo de la Relaciones Internacionales, la irrupción de la pandemia ocasionada por el coronavirus Covid-19 implicó la aceleración de una multiplicidad de debates a nivel global en torno a temas centrales para el devenir del orden internacional. Proliferan reflexiones acerca del impacto de la coyuntura sanitaria sobre el proceso de corrimiento del eje de poder mundial de Occidente hacia Oriente, y la economía global. Se interpela la continuidad de fenómenos que se creían definitivos por irreversibles, como la globalización o el empleo del multilateralismo en tanto herramienta de cooperación entre los Estados. Se deja al descubierto las dificultades de materialización que encuentra la gobernanza global, en alguna medida, a razón de la fragmentación y la dispersión del poder, así como del incremento del nacionalismo y el unilateralismo.

En este contexto de celeridad de los debates, en una mirada circunscripta a Latinoamérica y, específicamente, a América del Sur, es necesario hacer foco en un proceso que se venía desenvolviendo con anterioridad a la pandemia para examinar su evolución y potenciales implicancias. Por ello, este artículo se direcciona a sopesar la influencia de la crisis sanitaria por la expansión del virus Covid-19 sobre el proceso de militarismo que, desde mediados de 2019, muestra un incremento contundente. A tal fin, de manera muy sintética, se contextualiza el militarismo durante la posguerra fría y se explica por qué en 2019 se acelera dicho fenómeno. Luego, se examina el rol de las Fuerzas Armadas en el abordaje de la pandemia para, finalmente, esbozar algunas reflexiones parciales sobre el militarismo sudamericano como tendencia.

\section{El militarismo sudamericano como tendencia preexistente a la pandemia}

Como se sabe, el proceso de retorno a la democracia en Latinoamérica no se desarrolló de manera uniforme en todos los países. Específicamente en América del Sur, en casi todos los casos, las Fuerzas Armadas, como institución del Estado, preservaron importantes cuotas de poder e influencia sobre el sistema político, pero se retiraron de la primera línea de exposición pública, en tanto actores con un proyecto propio.

Por un lado, las instituciones castrenses mantuvieron amplios márgenes de autonomía para definir las cuestiones referidas a la política militar, en una relativización de los resultados de los procesos de modernización y profesionalización, que terminaron por versar preponderantemente sobre cuestiones de forma. En este sentido, resultó contraproducente que la reconfiguración del rol de las Fuerzas Armadas en la posguerra fría estuviese ligada al ámbito doméstico para paliar el avance del narcotráfico y el crimen transnacional organizado (Calderón, 2012). Al respecto de este punto tampoco deben olvidarse dos variables que resultaron determinantes. Por un lado, el contexto subregional, que combinaba el decreciente nivel de conflictividad interestatal y el avance de los mecanismos de diálogo político, con la escasez de recursos monetarios para invertir en Defensa, y las cada vez más acuciantes demandas económicas y sociales de las sociedades. Por el otro, la variable sistémica ligada al impulso que Estados Unidos le imprimió desde la tem- 
prana posguerra fría a la intervención de los militares en el abordaje de la agenda de seguridad pública (Calderón, 2018).

Por lo tanto, en este contexto, la supremacía civil logró concretarse de manera parcial en América del Sur en el sentido de que hubo un repliegue de los militares de la vida política de las sociedades pero no se alcanzó el estadio de conducción política del sector de la Defensa como ámbito estratégico del Estado. ${ }^{1}$ En paralelo con esto, y a grandes rasgos, la institución militar mantuvo ante la mirada de las sociedades civiles cuotas relevantes de prestigio y confianza. Con excepción de la Iglesia Católica, las Fuerzas Armadas y la policía conservan respectivamente alrededor del $44 \%$ y $35 \%$ de dicha confianza, muy por encima de los partidos políticos y los gobiernos, que con un $13 \%$ y $22 \%$, transitan por sus valores mínimos (Latinobarómetro, 2018).

Dado este contexto, y al ritmo del incremento de los problemas económicos, la pobreza, el desempleo y la ausencia del Estado como actor involucrado activamente en la consecución del bienestar de sus ciudadanos, América Latina se convirtió en la región más desigual del planeta. Los gobiernos, de una u otra manera e independientemente de su orientación político-ideológica, tendieron al empleo de los militares en el abordaje de la seguridad pública. Convocadas mayormente para combatir el fenómeno del narcotráfico, lo excepcional se fue institucionalizando (Verdes-Montenegro, 2019), y en todos los países, aunque en diferente medida y con rasgos diversos, se diluyó la diferencia entre seguridad y defensa. ${ }^{2}$ Frente a esto, no faltaron las voces que tempranamente advirtieron tanto sobre los riesgos como sobre la falta de pertinencia y eficacia de militarizar la agenda de seguridad interna y de policializar las Fuerzas Armadas. J. G. Tokatlian, A. Isacson, R. Diamint, H. Saint Pierre, solo por mencionar algunas de ellas, advirtieron sobre lo inadecuado del abordaje que se llevaba a cabo para una problemática cuyo trasfondo se liga a una situación de vulnerabilidad económica y social y se desarrolla en un contexto hemisférico que transita por un proceso de securitización (Buzan, Wæber y De Wilde, 1998).

Ahora bien, desde hace algunos años, se han generado situaciones en las que las distintas dirigencias políticas de turno han requerido la colaboración de los militares para gestionar escenarios cuya conflictividad podía resultar desestabilizante. $\mathrm{Si}$ bien tales gobiernos formalmente ganaron las elecciones, sus mandatos se encontraron rápidamente debilitados en contextos nacionales complejos, con problemas económico-sociales crónicos irresueltos, una institucionalidad débil y la creciente movilización, a veces con un componente violento, de la sociedad civil. Este estado de cosas es diferente del escenario que propició el militarismo del siglo XX, en el cual las Fuerzas Armadas tomaban el poder apoyadas por sectores minoritarios de la sociedad y se erigían en actores políticos con un proyecto político propio.

Dada esta singularidad, comenzaron a surgir conceptualizaciones específicas, como el nuevo militarismo de R. Diamint (Fisher, 2020) o el militarismo cívico de S. Rodríguez (2018). Asimismo, por ejemplo, S. Kurtenbach y A. Scharpf (2018) indican el nuevo amanecer de los militares más allá de la ideología del gobierno; A. Isacson (2019) subraya que los políticos le temen a la imposibilidad de recurrir 
al estamento militar frente a una crisis; B. Kyle y A. Reiter (2019) vincula la recuperación de poder con el incremento de funciones; S. A. Mejías (2015) asevera la existencia de una politización de las Fuerzas Armadas y la militarización de la democracia. A partir de los distintos aportes de la academia, en especial siguiendo el análisis de F. Verde Montenegro (2019), en este escrito se entiende el militarismo como un fenómeno distinto de los militares como actores de la sociedad y susceptible de ser asociado a una ideología cuya premisa es la mayor militarización, entendida como proceso de securitización en términos de la Escuela de Copenhague. Finalmente, el denominado fenómeno de khakiwashing, en tanto instrumentalización de los militares por parte del poder político, se sustenta en la confianza y aceptación que la sociedad deposita en el sector y que, en algunos casos, alcanza porcentajes altísimos, como en Uruguay (62\%), Ecuador (61\%), Brasil (58\%), Colombia (56\%), Chile (53\%) y Perú (44\%) (Latinobarometro, 2018).

\section{9: se acelera el militarismo}

El año 2019 en América del Sur puede asociarse a un momento de quiebre en virtud de distintos acontecimientos que tuvieron como actor protagónico a las Fuerzas Armadas e involucraron su aparición en el primer plano de la escena pública, como parte de una tendencia que se registra a nivel regional. ${ }^{3}$

A modo de síntesis, frente a la multiplicidad y heterogeneidad de tales situaciones en las que los militares fueron noticia, se puede decir que fueron convocados para reprimir protestas y manifestaciones de la sociedad civil en Ecuador, Chile, Colombia y Bolivia. En Venezuela y Brasil, por su parte, desarrollaron un rol concreto en la gestión del gobierno de turno, mientras que en Perú y Bolivia fueron requeridas para apoyar o remover al gobierno en funciones. Asimismo, hubo avances sobre la participación de las Fuerzas en el abordaje de la agenda de seguridad pública en Colombia y Paraguay y, desde la perspectiva de la retórica, en Brasil, Uruguay y Paraguay se produjeron pronunciamientos por parte de integrantes de las Fuerzas que ilustran su vocación por intervenir en el devenir de la política de sus respectivos países. ${ }^{4}$

Finalmente, Argentina fue la excepción frente a la tendencia militarista. La explicación versa en las características de la instauración de la supremacía y control civil sobre la institución castrense que se cumplimentó de manera consistente desde lo legal-institucional e ideacional-simbólico. Esto ocurrió, mayormente, dada la impronta en extremo desfavorable de las Fuerzas Armadas en el contexto de transición hacia la democracia ligada a las violaciones masivas contra los Derechos Humanos, la situación económica que dejó la administración militar y la falta de competencia profesional de los cuadros de máxima jerarquía durante la guerra de Malvinas (Calderón,2016).

Por consiguiente, frente a este contexto diverso en función de las particularidades de los casos nacionales, se delinea una tendencia preocupante, si consideramos la complejidad histórica de la vinculación entre la institución castrense y los Estados latinoamericanos en general. Resulta aún más evidente si se considera la postura que Estados Unidos, como potencia hemisférica hegemónica, tiene al 
respecto, susceptible de visibilizarse a través de las palabras de Craig Faller, Jefe del Comando Sur, a los militares venezolanos sobre lo esencial de su rol en la restauración de la esperanza (Infobae, 2019). Por ello, con la coyuntura instaurada por el Covid-19 como telón de fondo, en la cual la institución militar es requerida para desplegar diferentes tareas vinculadas al abordaje de una situación sanitaria excepcional, es necesario revisar la evolución del vínculo entre los gobiernos y las Fuerzas Armadas, así como el modo en que estas últimas son empleadas.

\section{0: los militares en el abordaje de la pandemia}

El pasado 3 de abril, la Directora de la Organización Panamericana de la Salud aseveró que se esperaba un tsunami de casos en América Latina y el Caribe (ESGC, 2020). El 26 febrero, Brasil registró el primer enfermo de Covid-19. El 7 de marzo Argentina comunicó la primera muerte y, para la tercera semana de ese mes, todos los países latinoamericanos tenían presencia del virus. Al momento de escribir estas líneas, el continente americano continúa siendo el epicentro de la pandemia. Sudamérica registra casos en ascenso y las proyecciones no son alentadoras.

Este escenario regional de desborde y colapso de la mayoría de los sistemas sanitarios era previsible, cuanto menos, en función de los indicadores de desarrollo de los países. De igual manera, era de esperar que las Fuerzas Armadas, en tanto instrumento del Estado, tendrían un rol destacado por necesario, tanto en función de sus capacidades logísticas como de los recursos humanos y materiales desplegados en los territorios nacionales, ambos con posibilidad de alistamiento y desplazamiento rápido.

Durante el mes de marzo, Venezuela, Ecuador, Chile, Colombia, Perú y Brasil declararon el estado de emergencia, sitio o de excepción. Todos los países cerraron sus fronteras y, a excepción de Venezuela, emitieron la emergencia sanitaria. Asimismo, todos los Estados de la subregión optaron por el aislamiento social obligatorio, excepto Brasil y Uruguay (Resdal, 2020). En este contexto, las Fuerzas Armadas fueron desplegadas por todos los países para afrontar la expansión del virus como amenaza a la salud pública y como parte de la labor militar en tiempos de paz. Según los datos relevados por la Red de Seguridad y Defensa de América Latina (2020), para la totalidad de la región durante marzo y hasta el 10 de abril, en América del Sur el 43\% de las tareas desempeñadas por los militares estuvieron vinculadas a la asistencia al sistema de salud. Además, un $25,4 \%$ de dichas tareas se relacionaban con la mantención del orden público y el control de las fronteras, el $18,3 \%$ con la distribución de alimentos y agua potable y el $9,8 \%$ se vinculó con la repatriación de nacionales en el extranjero.

Resulta significativo que, a excepción del caso argentino y brasileño, en los cuales las labores ligadas con el orden público realizadas por los militares representan, respectivamente, un $2 \%$ y $3 \%$ del total, para el resto de los países son entre el 23 y $44 \%$. Esta participación de las Fuerzas en tareas de orden público se comprende en el marco del proceso de repolicialización de las Fuerzas y del incremento del militarismo previo a la pandemia. En este sentido, todos los países - excepto 
Argentina- emplearon a la institución castrense para el control de las fronteras y la realización de patrullajes para supervisar el cumplimiento de la normativa vigente. Es dable recordar que esas medidas son gestionadas por las fuerzas de seguridad intermedia y la Policía, de acuerdo con la legislación nacional afianzada en el ejercicio de la supremacía civil sobre los militares quienes, además, han dado muestras de no estar dispuestos a retroceder en el camino de reconstrucción de su imagen ante la sociedad civil. Por su parte, la explicación sobre por qué Brasil tampoco involucró a los militares en tales patrullajes discurre por la circunstancia de que el gobierno no implementó el aislamiento social obligatorio.

No obstante, el despliegue en sí mismo de los militares sudamericanos como instrumento del Estado para la realización de tareas que, por ejemplo, en la legislación argentina se denomina de apoyo a la comunidad nacional y son parte de su labor subsidiario, no debería confundirse con una muestra del militarismo ni implicar su incremento. De hecho, si se revisa el accionar de las Fuerzas Armadas de otros países del globo, como Alemania, Italia, España, India, China, Corea del Sur -por mencionar algunos ejemplos-, puede apreciarse un rol activo ligado a un amplio abanico de actividades. Algunas de ellas ostentan un carácter asistencial para apuntalar el sistema sanitario y contener la crisis, como el transporte de material y efectivos, y la distribución de suministros médicos, hasta el traslado de cadáveres, y otras tareas se vinculan con el patrullaje de las calles y el controles en las fronteras (El País, 2020c).

Dado este estado de cosas, de acuerdo con la propuesta de F. Verdes Montenegro (2020), el debate sobre la conveniencia o no del empleo de los militares en el abordaje de la pandemia debiese ser reemplazado por una revisión exhaustiva del modo en el que las Fuerzas llevan adelante su actuación. Esto se da con el objetivo de observar cómo reacciona la institución militar frente al incremento de la dependencia por parte del poder político que implica su convocatoria. Se parte de la premisa de que el Estado debe poder realizarla, y debe ejercer la conducción política y el control sobre las Fuerzas Armadas como una de sus tantas instituciones con carácter operativo. Como afirma A. Varas, "la mayoría de las constituciones democráticas contemplan estados de excepción cuando sus países enfrentan catástrofes como las del covid-19 y las fuerzas armadas son llamadas a colaborar", quedando su accionar sujeto al control parlamentario y de la sociedad civil para evitar que se extralimiten (citado en Aguirre, 2020).

En línea con esto, hay dos cuestiones merecedoras de un seguimiento más exhaustivo. Por un lado, atendiendo a las tareas de control y vigilancia, como afirma A. Isacson (2020), la coyuntura instaurada por el Covid-19 abre la puerta a una potenciación de la repolicialización de los militares como tendencia regional preexistente, que alcanza a casi todos los Estados sudamericanos, con independencia del nivel de desarrollo del militarismo y las distancia de su misión principal de Defensa. Por otro lado, una segunda cuestión a revisar sería si el escenario instaurado por la pandemia potencia la advertencia de R. Diamint acerca de que si los gobiernos son incapaces de cumplir con sus deberes y continúan requiriendo a los militares, estos podrían reposicionarse en la política (Isacson, 2020). Si tenemos 
en consideración el pasado autoritario y golpista de las Fuerzas, así como su presente reciente con niveles importantes de influencia política y autonomía, dicho reposicionamiento sería el riesgo más acuciante que correrían las democracias con militares cuyos desempeños en situaciones circunstanciales pueden tornarse permanentes, como afirma A. Varas (citado en Aguirre, 2020).

Para finalizar, cabe apreciar que el contexto de pandemia por sí mismo provoca un retraimiento de la democracia, pero desligado del militarismo como variable condicionante. Ejemplo de ello es que el Índice de riesgo de retroceso democrático presentado por el proyecto V Democracy, que mide el impacto político de la pandemia, emplea indicadores que excluyen a los militares y su despliegue en el terreno (Azpuru, 2020). ${ }^{5}$ Sin embargo, y frente a las perspectivas de una pospandemia marcada por una crisis económica que se espera que tenga una severidad que desde hace décadas no se vivencia, resulta válido preguntarse por cuánto tiempo el descontento social puede mantenerse pausado (Dasso, 2020) y qué rol tendrán los gobiernos de turno y las Fuerzas Armadas frente a un nuevo estallido de las sociedades.

\section{Tras el velo del Covid-19, una certeza con muchas formas posibles}

En una pospandemia como la pronosticada, con altos niveles de incertidumbre institucional enraizada con la vulnerabilidad social y el deterioro de la economía, para la que se pronostica una caída en la actividad del -9,1\% (CEPAL, 2020), es altamente probable que el militarismo incentivado por la mayoría de los gobiernos de Sudamérica se vea incrementado. Esto puede darse en función del pasado reciente de las Fuerzas, el proceso que atravesaron durante la posguerra fría, el apoyo político que reciben por parte de la potencia hegemónica hemisférica, la aceleración en 2019 de la tendencia desplegada durante el siglo XXI y, aunque más no sea, por la circunstancia de que en la coyuntura actual no hay chances de que ningún gobierno salga fortalecido. Por lo tanto, los militares como recurso seguirán siendo convocados y, también, para concretar tareas ligadas al orden público. Esta situación, sin dudas, va en detrimento de la democracia y la estabilidad institucional. A su vez, aumenta las posibilidades de un reposicionamiento político del sector castrense, aunque ello no implique formar parte visible de los gobiernos.

De ser así, las dudas acerca del impacto de la pandemia sobre el militarismo como tendencia preexistente se disiparían, y darían paso a un abanico de modalidades posibles acerca de la forma en la cual dicho militarismo se fortalecerá atendiendo a las particularidades de los casos nacionales. Asimismo, el comportamiento de la sociedad civil frente al militarismo resultará determinante. Piénsese que las movilizaciones de Chile a fines de 2019 demostraban una sorpresiva irreverencia frente al accionar represivo de las Fuerzas Armadas y los Carabineros, o cómo la sociedad colombiana manifestó un derrumbe sin precedentes en la percepción históricamente favorable de los militares -del $85 \%$ cayó a un $48 \%$ (El País, 2020b)-, al tiempo que la Argentina seguiría presentándose como una excepción a la extensión de esa tendencia. 
Por otra parte, en una mirada más amplia, a nivel subregional es de esperar un escenario de mayor complejidad, relacionado con la modificación en las percepciones que acarrean medidas como los blindajes fronterizos y la mayor incidencia de las Fuerzas Armadas en los gobiernos. Esto, incluso, puede afectar las posibilidades de diálogo político con respecto a situaciones conflictivas como la de Venezuela y Bolivia. Propagaría la incertidumbre acerca del futuro de la Sudamérica como zona de paz, lo cual es poco conveniente en el contexto de puja de poder entre Estados Unidos y China para definir los términos de la transición del orden internacional liberal a uno cuyo epicentro geográfico sea Oriente. Consecuentemente, todo parece indicar que el militarismo sudamericano ha de continuar su derrotero, aunque temporalmente lo haga tras el velo del Covid-19.

\section{Referencias}

1.Por conducción política de la defensa se entiende la gestión integral del Estado sobre esa área para elaborar y supervisar la implementación de la Política de Defensa como política pública (Calderón, 2016). Por otra parte, la supremacía civil se asocia con la idea de subordinación sobre las Fuerzas Armadas a través de, como mínimo, la eliminación de la presencia de los militares en los puestos de poder por fuera del área de la Defensa. En aquellos puestos en los que el expertise militar tiene un rol central, se procura el reconocimiento del liderazgo civil en el proceso de toma de decisiones políticas..

2. Hasta hace algunos años, la referencia de Uruguay, Argentina y Chile era obligada para indicar el sostenimiento de la diferencia entre seguridad y defensa y la excepción en la tendencia regional al involucramiento de los militares en el combate contra el narcotráfico. No obstante, las políticas desplegadas por los gobiernos durante los últimos años, así como algunos hechos puntuales, indican que la separación de esos ámbitos dista de ser tan tajante como lo era en otros tiempos (Calderón, 2019).

3. El alcance regional del crecimiento del militarismo como tendencia se observa a través de incontables eventos, como los registrados en Guatemala con la Comisión Internacional contra la Impunidad de NU; en México con la creación de la Guardia Nacional y en Honduras que, además del golpe de 2009, ha reprimido con el Ejército las protestas sociales que han surgido.

4. Sin intenciones de exhaustividad, se reseñan los hechos más relevantes. Se toman como fuentes eventos de público conocimiento que pueden rastrearse en las páginas web de los periódicos $B B C$ Mundo y El País. En este sentido, en Brasil, el Presidente Jair Bolsonaro mostró su cercanía con el sector militar. Justificó el golpe de Estado de 1967 y posicionó a 2.897 militares en cargos civiles con funciones de tercer y segundo escalafón en la administración federal, además de la jefatura de 8 ministerios. En Colombia, Iván Duque militarizó partes del país y otorgó facultades extraordinarias a gobiernos locales para mantener el orden durante el paro nacional y las movilizaciones masivas de noviembre, en un contexto donde la participación de los militares en la erradicación de cultivos ilícitos ya había causado enfrentamientos con los campesinos y, además, se conoció la campaña de vigilancia e intimidación de unidades de inteligencia militar contra periodistas, políticos, jueces y defensores de Derechos Humanos, así como más de un centenar de casos de abuso sexual a menores de comunidades indígenas. En Ecuador, Lenin Moreno declaró en octubre el estado de excepción y toque de queda por el estallido de protestas protagonizadas por indígenas, sindicatos y estudiantes tras la publicidad de las medidas económicas de ajuste pactadas con el Fondo Monetario Internacional. En Perú, el Presidente Martín Vizcarra Cornejo, con el respaldo de las Fuerzas Armadas y la Policía, disolvió el Congreso y llamó a elecciones Parlamentarias frente a la inminente decisión de este último de inhabilitarlo en sus funciones en el marco de la crisis política iniciada en 2016 por los escándalos de corrupción. En Bolivia, Evo Morales fue intimado a renunciar por la cúpula militar con la excusa de la necesidad de pacificar el país, dadas las protestas callejeras en contra de los resultados electorales, los policías, declarados en rebeldía y la renuncia de ministros y funcionarios frente a la violencia creciente. No obstante, tras la asunción de Jeanine Áñez, se extendió la protesta contra el golpe de Estado y el accionar represivo 
de las Fuerzas Armadas en las operaciones combinadas fue denunciado por la Comisión de Naciones Unidas para los Derechos Humanos y Human Rights Watch. En Chile, por su parte, Sebastián Piñera, con un léxico belicista, declaró el estado de excepción y toque de queda frente al estallido social que ocasionó el aumento del precio del Metro, pero que se ancla en la situación económica y social crítica de la mayoría de la población. Las manifestaciones pacíficas multitudinarias, así como los episodios de violencia desarrollados en varias ciudades durante semanas, fueron abordados por las Fuerzas Armadas, Carabineros y policías. Todos ellos fueron denunciados por violaciones a los Derechos Humanos por Human Rights Watch, Amnistía Internacional, el Instituto Nacional de Derechos Humanos de Chile y NU. En Paraguay, Mario Abdo Benítez transfirió la custodia de las penitenciarías a las Fuerzas Armadas, lo cual provocó la manifestación de la Policía contra la ampliación del rol de los militares. Además, su silencio frente al homenaje de Bolsonaro a Stroessner y, luego, la firma del acuerdo sobre Itaipú pusieron al Presidente en el centro de las críticas por parte de la oposición, y quedó al borde del juicio político. En Uruguay, Tabaré Vázquez tuvo un año de roces con líderes militares que criticaron políticas gubernamentales, como el sistema de pensiones, y a ciertos jueces por su trato para con los efectivos vinculados con violaciones a los Derechos Humanos durante la dictadura. Por esto, fueron destituidos el comandante en jefe del Ejército, Manini Ríos, quien luego se postuló como candidato presidencial, y su reemplazo, que se negó a repudiar los hechos ocurridos durante dicho gobierno de facto. También removieron de sus cargos al ministro y viceministro de Defensa y a dos generales. Finalmente, en Venezuela, como sucede desde 1999, Nicolás Maduro continuó gobernando en función de un proyecto nacional que parte de la unión cívico-militar y conduce a la politización y partidización de las Fuerzas Armadas.

5. El proyecto V Democracy se focaliza en indicadores como la libertad de expresión, la expansión del poder del Ejecutivo, la imposición de límites al Legislativo y al poder Judicial, si se derogaron derechos ciudadanos o se han adoptado medidas discriminatorias contra ciertos grupos, si se impusieron medidas de emergencia en forma arbitraria o con abuso de poder o se restringieron los procesos electorales.

\section{Bibliografía}

Aguirre, M. (2020). Coronavirus: por qué la pandemia de covid-19 podría fortalecer los autoritarismos y debilitar las democracias. BBC Mudo (08/04/2020). Disponible en: https://www.bbc.com/mundo/ noticias-internacional-52184947

Azpuru, D. (2020). El riesgo de retroceso democrático en América latina durante la pandemia. Agenda Pública. Disponible en: http://agendapublica.elpais.com/el-riesgo-de-retroceso-democratico-en-america-latina-durante-la-pandemia/

Buzan, B., Wæver, O. y De Wilde, J. (1998). Security: A New Framework for Analysis. London, UK: Lynne Rienner.

Calderón, E. (2012). La impronta legal de la participación de las Fuerzas Armadas en los asuntos de seguridad pública: el caso de la lucha contra el narcotráfico como práctica extendida en América del Sur. Revista Latinoamericana de Seguridad Ciudadana, diciembre 97-109. Quito, Ecuador: URVIO, FLACSO.

Calderón, E. (2016). La conducción política de la Defensa en Argentina durante el kirchnerismo y su incidencia en la inserción internacional: miscelánea de dudas razonables y certezas inconclusas. Revista Relaciones Internacionales, edición especial, año 25, no. 50, 189-202. La Plata, Argentina: UNLP Calderón, E. (2018). Fuerzas Armadas y narcotráfico en Argentina: ¿un debate inconducente?. Revista de Estudios en Seguridad Internacional, Vol. 4, No. 2, 207-225, diciembre.

Calderón, E. (2019). Argentina ¿bastión regional de la separación entre Seguridad y Defensa? La lucha contra el narcotráfico en la frontera norte?. Revista Científica General José María Córdova, 483-501, Julio. Bogotá, Colombia.

CEPAL (Comisión Económica para América Latina y el Caribe) (2020). Contracción de la actividad económica de la región se profundiza a causa de la pandemia: caerá $-9,1 \%$ en 2020. Disponible en: https://www.cepal.org/es/comunicados/contraccion-la-actividad-economica-la-region-se-profundiza- 
causa-la-pandemia-caera-91

Dasso, A. (2020). Los militares en tiempos de pandemia. Nueva Sociedad. Disponible en: https://nuso. org/articulo/los-militares-en-tiempos-de-pandemia/

ESGC (Escuela Superior de Guerra Conjunta de las Fuerzas Armadas) (2020). Informe abril del Observatorio de la crisis Covid-19. Buenos Aires, Argentina. Disponible en: http://www.esgcffaa.edu.ar/ esp/publicaciones-covid.php

Fisher, M. (2020). Los dirigentes asediados de Latinoamérica recurren a los militares. The New York Times (02/11/2019). Recuperado de https://www.nytimes.com/es/2019/11/02/espanol/america-latina/ militares-america-latina.html

Infobae (2019). La carta del jefe del Comando Sur de EEUU a los militares venezolanos: "Tienen un rol esencial en la restauración de la esperanza". Infobae (24/06/2019). Disponible en: https://www.infobae.com/america/ venezuela/2019/06/24/la-carta-del-jefe-del-comando-sur-de-eeuu-a-los-militares-venezolanos-tienenun-rol-esencial-en-la-restauracion-de-la-esperanza/

Isacson, A. (2019). ¿Cómo está afectando el control civil de los militares la agitación política de América Latina?. WOLA. Disponible en: https://www.wola.org/es/analisis/como-esta-afectando-el-controlcivil-de-los-militares-la-agitacion-politica-de-america-latina/

Isacson, A. (2020). In Latin America, COVID-19 Risks Permanently Disturbing Civil-Military Relations. WOLA. Disponible en: https://www.wola.org/analysis/latin-america-covid-19-civil-militaryrelations-policing/

Kyle, B. J. y Reiter, A. G. (2019). A New Dawn for Latin American Militaries. NACLA Report on the Americas, no. 52: 1, 18-28.

Kurtenbach, S. y Scharpf, A. (2018). The Return of the Military. GIGA Focus Latin America, no. 7. Hamburgo, Alemania: German Institute of Global and Area Studies.

Latinobarómetro (2018). Informe 2018. Disponible en: www.latinobarometro.org $\square$ latdocs INFORME_2018...

Mejías, S. A. (2015). La adaptación de las fuerzas de seguridad ante la violencia y el crimen organizado en América Latina. Cuaderno de Estrategia, 171. Madrid, España: Instituto Español de Estudios Estratégicos. Disponible en: http://www.ieee.es/publicaciones-new/cuadernos-de-strategia/2015/ Cuaderno_171.html

RESDAL (Red de Seguridad y Defensa de América Latina) (2020). La labor de fuerzas militares en contexto de Covid-19. RESDAL, no. 2, julio. Disponible en: https:/www.resdal.org/assets/resdal-boletin_covid-19n2_esp_final.pdf

Rodríguez, S. (2018). Building Civilian Militarism: Colombia, Internal War, and Militarization in a Mid-Term Perspective. Security Dialogue, nº 49, 109-122.

Verdes Montenegro, F. (2019). La (re)militarización de la política latinoamericana. Origen y consecuencias para las democracias de la región. Documentos de Trabajo, nº 14. Madrid, España: Fundación Carolina. Disponible en: https://doi.org/10.33960/AC_34.2020

Verdes Montenegro, F. (2020). Excepcionalidad y covid-19: un test democrático para América Latina. Documentos de Trabajo, n ${ }^{\circ}$ 44. Madrid, España: Fundación Carolina. Disponible en: https://doi. org/10.33960/AC_34.2020

Emilse Calderón, "El militarismo sudamericano tras el velo del Covid-19". Revista Temas y Debates. ISSN 1666-0714, año 24, número especial, julio-diciembre 2020, pp. 397-406. 